\title{
Leadership competencies in healthcare
}

\author{
Valchin Garov ${ }^{1}$, Svetoslav Garov², Dimitar Gugutkov ${ }^{1}$
}

1. Multi-profile Hospital for Active Treatment "Doverie";

2. Faculty of Public Health, Medical University of Sofia;

\begin{abstract}
Marketing of hospital services is among the main priorities of healthcare managers. A number of healthcare establishments, however, still lack a marketing department.

The paper analyzes data from a survey carried out among 100 medical specialists and employees at Medical Complex Doverie in Sofia, Bulgaria.

Results show that the management of a healthcare establishment requires a high level of competence of the healthcare manager in every field. It requires in-depth knowledge, broad-mindedness, as well as wide general knowledge.
\end{abstract}

Keywords: marketing of healthcare establishments, healthcare management, patient, medical employees.

\section{Introduction}

Competence is the result of three components: acquired knowledge, accumulated experience and developed skills. (2) Enhancing competence is a continuous process driven by the inner motivation of a person to perform better and better in their field of work. Knowledge and experience should match the professional goals by supporting the achievement of specific results. $(9,10)$

Basic manager competencies are in fields defined as priorities for manager development. $(1,7)$ The level of informedness and ability to conceptualize are indicators not only of the existence or lack of knowledge in the respective field, but also of the extent to which they are lasting and sustainable categories of 
consciousness. (6) Without information and training on scientifically established regularities, effective behavioral models and their value dimensions, one cannot acquire skills and improve the qualities required for efficient and successful management. $(5,8)$

There are 6 major factors of basic management competencies:

1. Time management

2. Goal management

3. Communication and organizational behavior

4. Basic management skills

5. Developing an efficient team

6. Project management and priority implementation. (3)

\section{Aim}

The aim of the studies is to analyze the marketing approaches and leadership qualities of the management of Medical Complex "Doverie" in Sofia.

To this end, a survey was carried out within the period January - December 2017 among 100 medical specialists and employees at Medical Complex "Doverie" in Sofia. The respondents work in different wards of the hospital and are directly related to the activities, policy and development of a working marketing-management strategy. They represent the main group providing medical services to the patients and are the carriers of the organization's company culture.

\section{Results and discussion}

The distribution of the respondents by occupation is as follows: $52 \%$ of the specialists are doctors, $26 \%$ are nurses, $12 \%$ are rehabilitation therapists and $10 \%$ - other employees. (Figure 1).

Figure 1. Surveyed medical specialists by occupation.

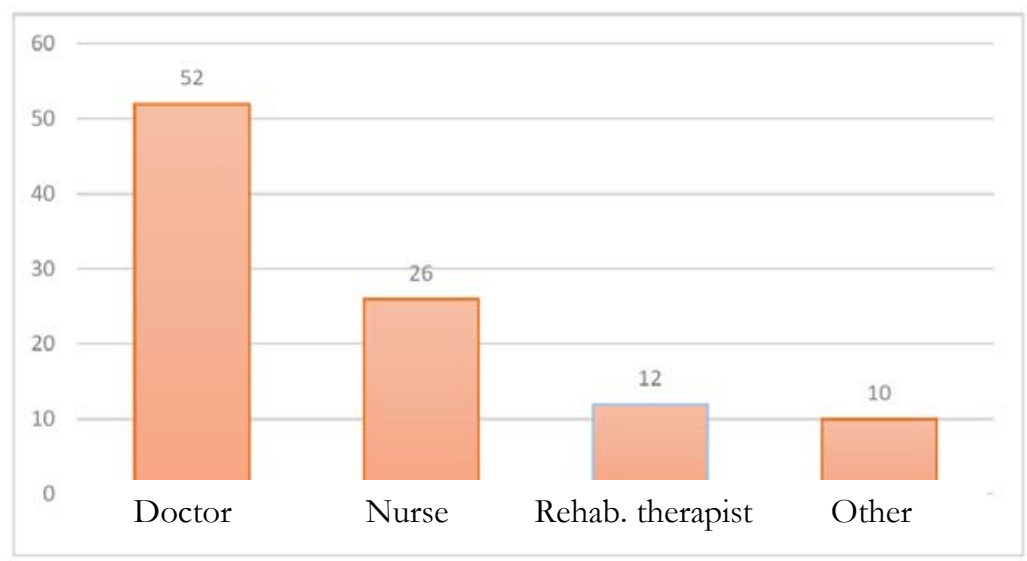


The findings regarding the opinion of MC Doverie's employees about the degree of implementation of professional management in the healthcare system management in Bulgaria are shown in Figure 2. Most of the respondents, $48 \%$, believe that this has been done to a high degree. Not implemented at all as an element of the healthcare management culture is the answer given by $5 \%$, and $24 \%$ believe it has been implemented to some degree. Only $5 \%$ were unable to judge.

Figure 2. Respondents' opinion regarding the degree of implementation of professional management in the healthcare system management.

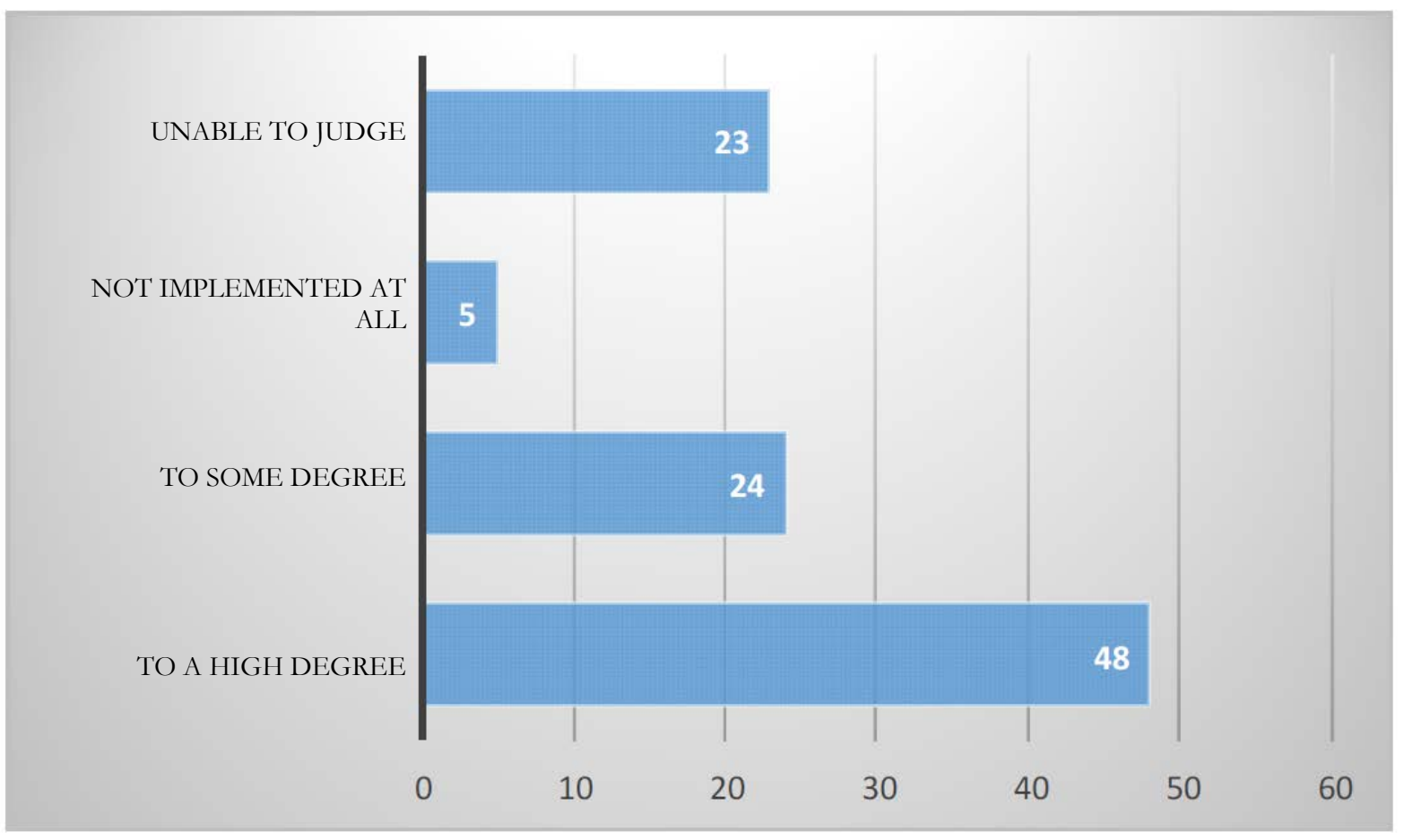

When asked about the possibility for changes in the healthcare services provided to the population in Bulgaria if the healthcare system is demonopolized, $98 \%$ of the employees firmly believe that free competition and free market, and most of all, the possibility to choose an insurance institution, would improve conditions for the population as users of healthcare services and improve the quality of work for medical specialists.

Figure 3. Respondents' opinion regarding the possibility for changes in healthcare services if the healthcare system in Bulgaria is demonopolized. 


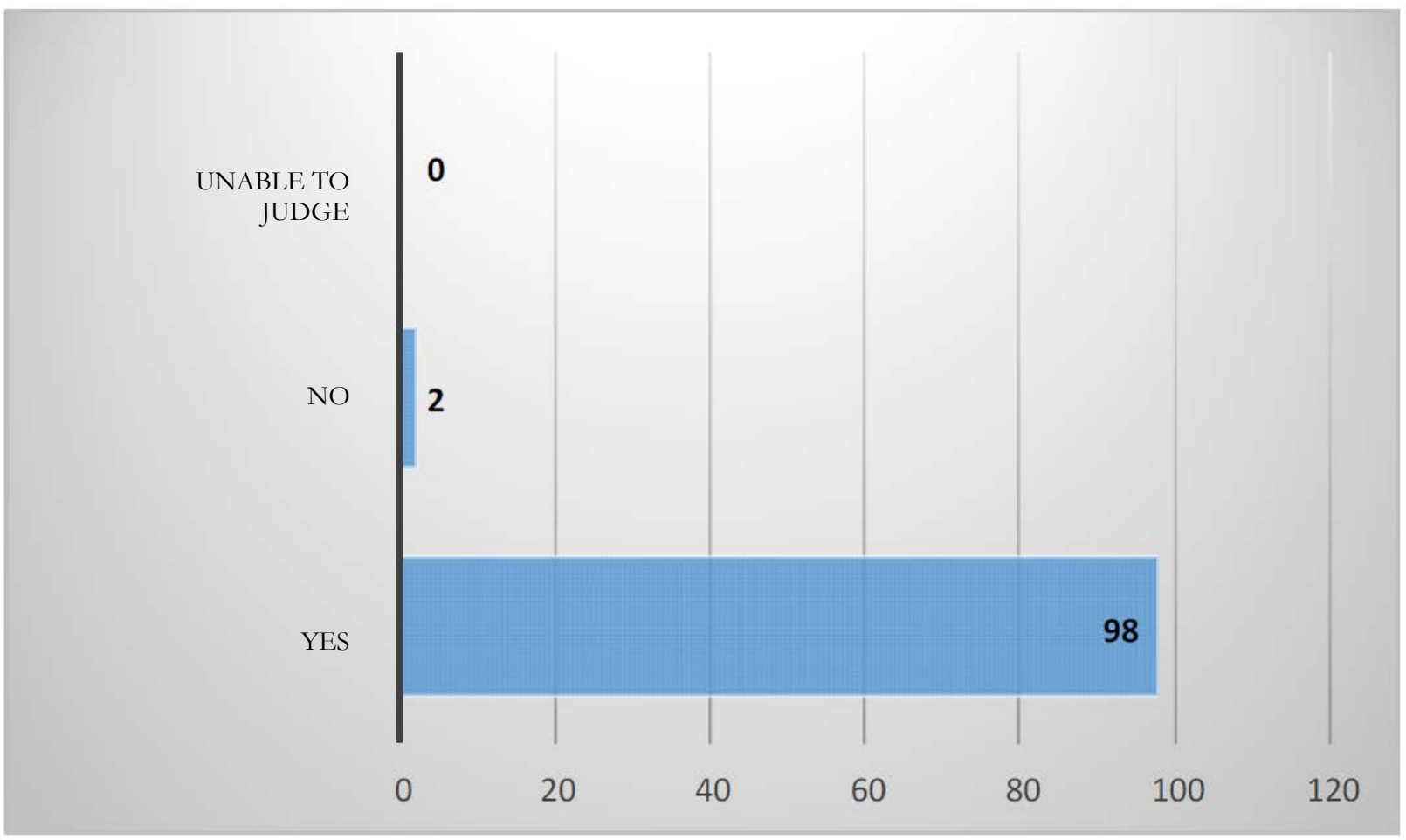

Most of the respondents think that the minimum educational qualification for the position of hospital director is a medical degree plus a Master's degree in healthcare management - $64 \%$, followed by those who selected "medical degree with a recognized specialty" (32\%). The percentages of those who think a degree in Economics or Law plus a healthcare management qualification course (23\%) and a degree in Economics or Law plus a Master's degree in healthcare management $(28 \%)$ are close. Every twentieth respondent thinks a Master's degree in healthcare management is sufficient. (Figure 3).

The next table shows the data from the survey concerning the degree of importance of the leadership competencies required for a manager in the field of healthcare. A distinctive feature of the successful manager is the assessment of a set of criteria (and not the assessment of just one criterion). This group also includes: personal qualities, motives, experience and behavioral characteristics. In addition, enhancing qualifications leads to enhancement of competencies and develops highly competent managers. The main competencies a modern manager should have are:

- Goal and management activity;

- Management of colleagues;

- Human resources management;

- Leadership.

In order to acquire management competencies, managers should gain a certain practical experience. The capabilities, knowledge and personal qualities are inherent to managers at the very start of their career as such. 
Table 1 shows the results from the data obtained by the survey. The highest percentage of respondents (76\%) identify the factors "Personal organizational efficiency" and "Leadership action style" as very important. $71 \%$ believe that this is the criterion "Achieving results". As an important factor, "Leadership of others" ranks first (65\%), followed by "Leadership of achievements and of change" (55\%), and "Achieving results and self-improvement" ranks third with $28 \%$. Neutral respondents are less than $10 \%$. The analysis so far firmly confirms the high competencies of the surveyed employees of MC Doverie regarding the importance of factors defining the leadership competencies required for a manager in the field of healthcare.

Table 1. Relative share of respondents by degree of importance of the leadership competencies required for a manager in the field of healthcare.

\begin{tabular}{|l|c|c|c|c|c|}
\hline \multicolumn{1}{|c|}{ Factors } & $\begin{array}{c}\text { Very } \\
\text { important }\end{array}$ & Important & Neutral & $\begin{array}{c}\text { Slightly } \\
\text { important }\end{array}$ & $\begin{array}{c}\text { Not } \\
\text { important }\end{array}$ \\
\hline $\begin{array}{l}\text { Self-improvement and } \\
\text { development of } \\
\text { personal qualities and } \\
\text { skills }\end{array}$ & $61 \%$ & $28 \%$ & $7 \%$ & $4 \%$ & - \\
\hline $\begin{array}{l}\text { Personal organizational } \\
\text { efficiency }\end{array}$ & $76 \%$ & $22 \%$ & $2 \%$ & - & - \\
\hline Leadership of others & $22 \%$ & $65 \%$ & $7 \%$ & $6 \%$ & - \\
\hline Leadership Action Style & $76 \%$ & $15 \%$ & $7 \%$ & $2 \%$ & - \\
\hline $\begin{array}{l}\text { Leadership of } \\
\text { Achievements and of } \\
\text { Change }\end{array}$ & $39 \%$ & $55 \%$ & $2 \%$ & $4 \%$ & - \\
\hline Achieving results & $71 \%$ & $28 \%$ & $1 \%$ & - & - \\
\hline
\end{tabular}

The question about the respondents' assessment of the effectiveness of implementation of marketing policies and concepts in MC Doverie rendered the predominant response that it is rather effective (63\%). $15 \%$ of employees evaluate the implementation as effective. Almost one fifth of the employees do not think marketing programs are applied sufficiently. (Figure 4).

Figure 4. Degree of effectiveness of implementing marketing policies in the activities of MC Doverie. 


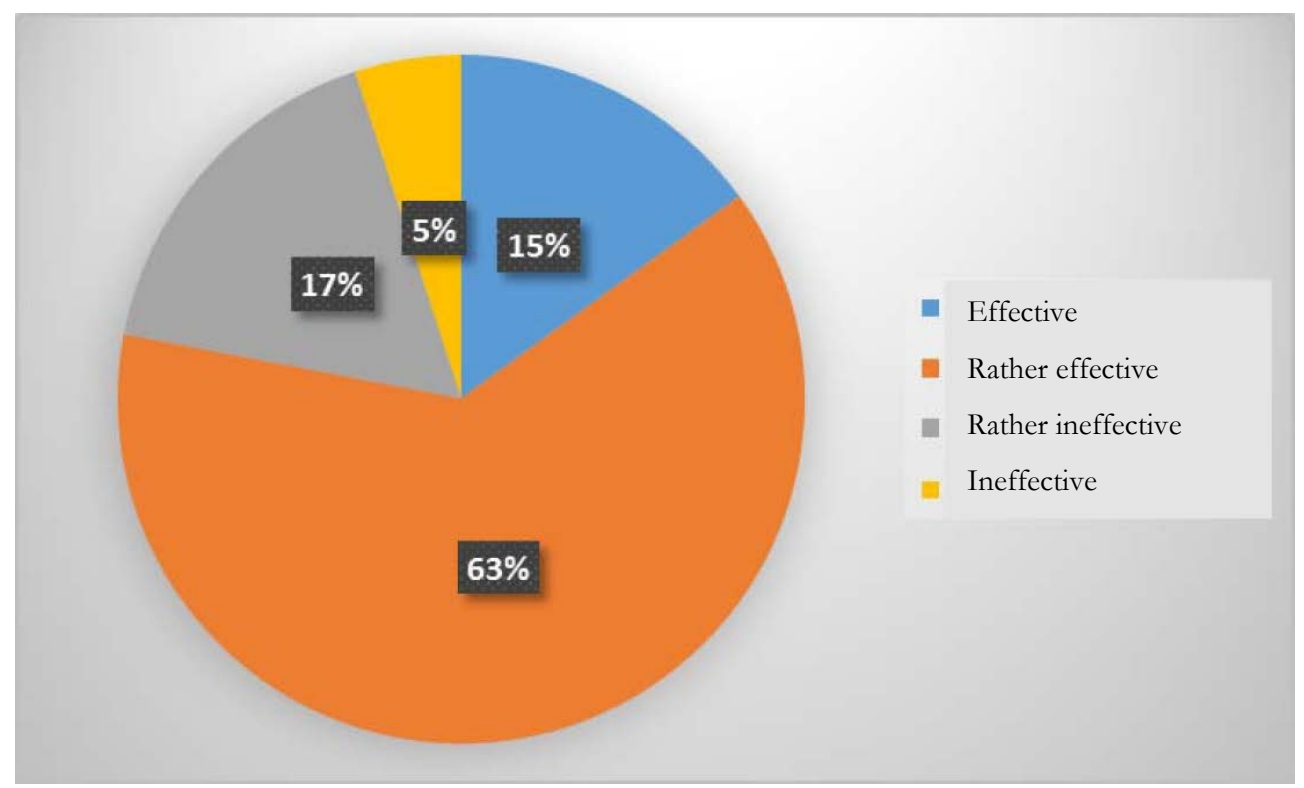

Patient satisfaction is one of the most important criteria for the assessment of a healthcare establishment and the work of medical specialists. That is why we asked the employees what influences this assessment (Figure 5). The highest percentage - 89 - believe it is the attitude of the professional providing services to the patient. $72 \%$ think that a motivated staff provides better services and, respectively, the patient is more satisfied. More than half ( $56 \%$ ) identify the way of working as one of the important factors which impact patient satisfaction. The attitude of the professional providing the service towards the patient's relatives and working in a team of professionals were identified by the lowest number of respondents $-13 \%$ and $12 \%$, respectively.

Figure 5. Employees' opinion about the most important factors affecting patient satisfaction.

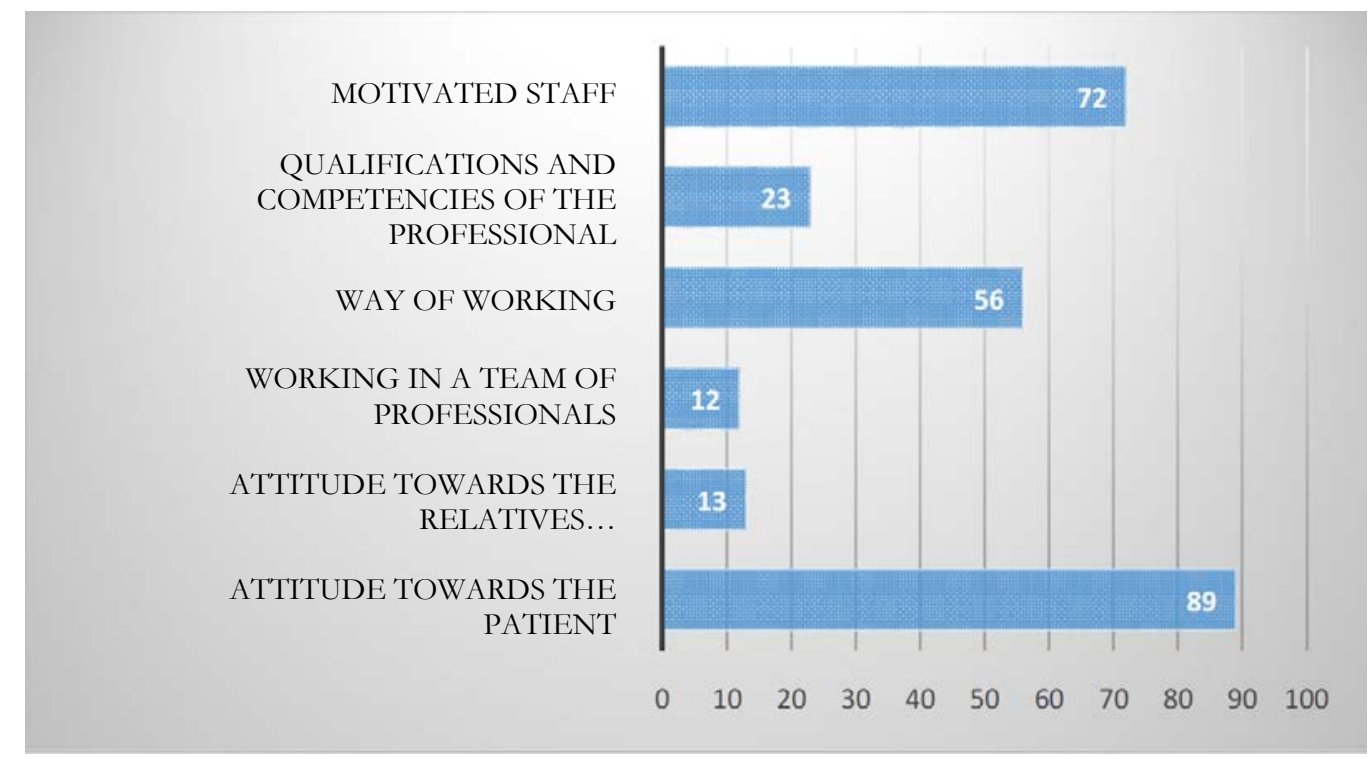


Figure 6 shows the distribution of employees in terms of their opinion about the leadership competencies of the hospital's management team. $48 \%$ believe that the management has leadership competencies to a high degree. $46 \%$ define them as incomplete, and $6 \%$ think such are lacking.

\section{Figure 6. Employees' opinion about the leadership competencies of the management team of MC Doverie.}

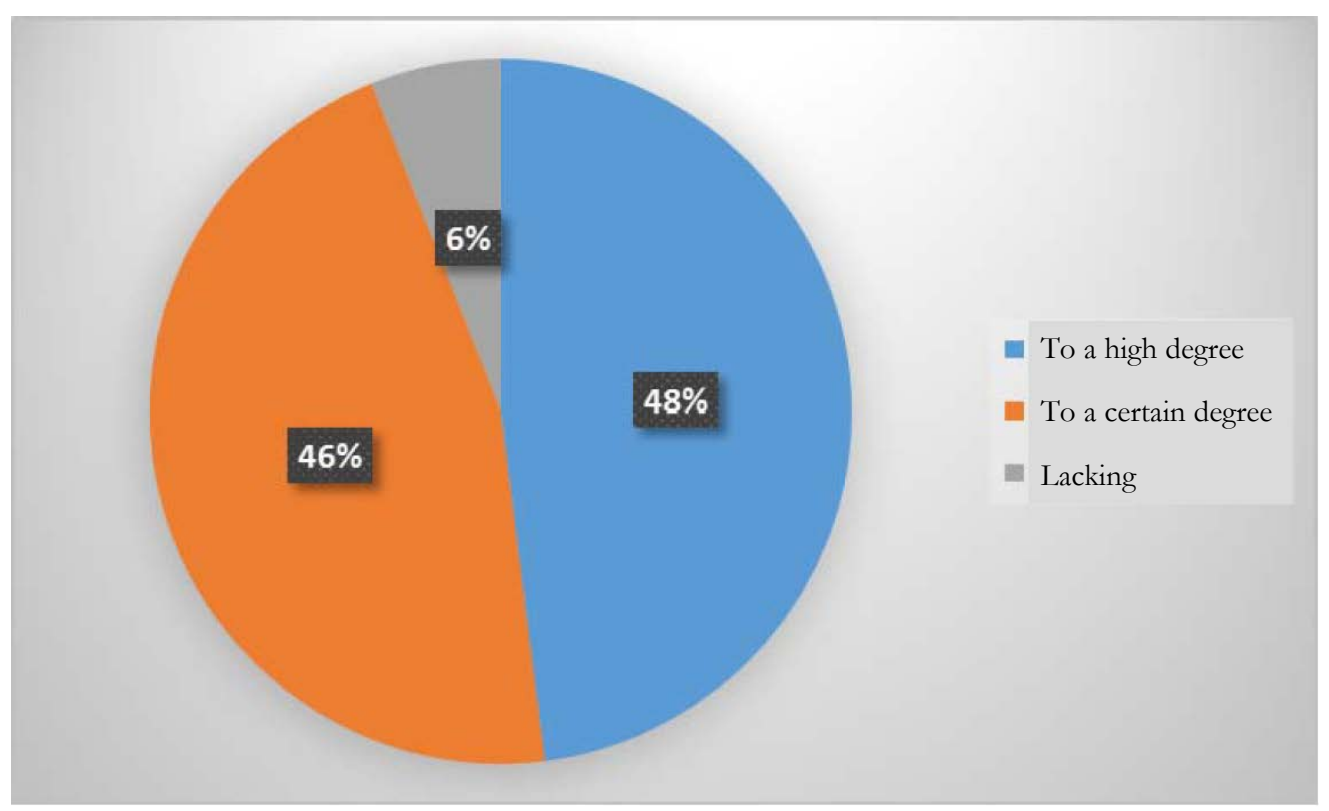

The presence of leadership competencies and their impact as an element of the employees' motivational policy are identified by $98 \%$ of the respondents. Only $2 \%$ think the presence of such qualities has a partial impact.

The findings regarding the opinion of the surveyed employees of MC Doverie about the degree of importance of each skill the manager of a healthcare establishment should have, show that respondents identify as extremely important "Productivity and pro-activeness" (93\%), "Taking responsibility" (91\%), followed by "Team work" - 86 \%, "Defining goals" (86\%), and "Planning and organizing" (81\%). A large relative share of the employees identified as very important skills "Showing empathy" (73\%), "Use of technologies" (54\%) and "Will for change" (48\%). "Written communication" was defined as neutral by 58 $\%$ of respondents. The results confirm the thesis that the management should have complex skills in order to perform excellently as managers.

\section{Conclusion}

According to V. Borisov, Z. Glutnikova and Ts. Vodenicharov, every manager should have developed the following types of skills: 
1. Conceptual - skills for justifying and developing concepts for the management and development of the managed system. These skills are based on the presence of competent professional and management views. It can be said that a manager without a vision is an inefficient mediocre administrator.

2. Communicative - for interpersonal relations and social contacts in the management process.

3. Technical - handling documentation, organizing and holding meetings, computer skills, analysis of statistical information.

4. Team work - skills for recruitment and development of a management team through which the manager carries out their management functions. (4)

The analysis of the survey data shows that the management of a healthcare establishment requires high competence of the healthcare manager in every field. It requires in-depth knowledge and broadmindedness, as well as wide general knowledge. All these qualities and skills of the management team can be obtained through continuous education and accumulation of practical leadership competencies. Without good management, the organization's activities would become chaotic and threaten its existence.

\section{References}

1. Balkanska P. Is there a shortage of leaders in healthcare - can it be overcome? [Article in Bulgarian] Health management. 2010; 2:39-44.

2. Balkanska P. Psychological approaches in healthcare management. [Book in Bulgarian] 2009.

3. Balkanska $P$, Savova $Z$. The manager as a leader, or how to combine the two positions. [Article in Bulgarian] Health management. 2003; 3(5):11-14.

4. Borisov $\vee$ et al. New public healthcare. [Book in Bulgarian] 1998.

5. Drucker P. The coming of the new organization. Reprinted in Harvard Business Review on knowledge management. Boston: Harvard Business School Press. 1998:1-19.

6. Grifith J, White K. The revolution in hospital management. Journal of Healthcare Management. 2005; 5:49-55.

7. Kostadinova T. Marketing approaches and hospital management [Article in Bulgarian] Health economics and management. 2001; 2:3-12.

8. Porter M, Teisberg E. Redefining competition in healthcare. Harvard Business Review. 2004; 82(6):65-77.

9. Spiridonov $S$, Trendafilova $P$. Challenges before the professional career of human resources in a private hospital. [Article in Bulgarian]. 2009:204-208.

10. Vodenicharov Tz. Professional healthcare management has no alternative. [Article in Bulgarian] Medical meridians. 2014; 2:3-7.

\section{Corresponding author:}

Dr. Valchin Garov, MD, PhD

Director of Multi-Profile Hospital "Doverie"

1632 Sofia, district Ovcha Kupel 2,

2 Friedrich Grunanger Str.

email: v.garov@mbal.doverie.bg 